\title{
Effect of position feedback during task-oriented upper-limb training after stroke: Five-case pilot study
}

\author{
Birgit I. Molier, MSc; ${ }^{1 *}$ Gerdienke B. Prange, PhD; ${ }^{1}$ Thijs Krabben, MSc; ${ }^{1}$ Arno H. A. Stienen, PhD $;^{2-3}$ \\ Herman van der Kooij, PhD; ${ }^{3}$ Jaap H. Buurke, PhD, PT; ${ }^{1}$ Michiel J. A. Jannink, PhD; ${ }^{1,3}$ Hermie J. Hermens, \\ $\mathbf{P h D}^{1,4}$ \\ ${ }^{1}$ Roessingh Research and Development, Enschede, the Netherlands; ${ }^{2}$ Department of Biomedical Engineering, Robert R. \\ McCormick School of Engineering and Applied Science, Northwestern University, Evanston, IL; Departments of \\ ${ }^{3}$ Biomechanical Engineering and ${ }^{4}$ Biomedical Signals and Systems, University of Twente, Enschede, the Netherlands
}

\begin{abstract}
Feedback is an important element in motor learning during rehabilitation therapy following stroke. The objective of this pilot study was to better understand the effect of position feedback during task-oriented reach training of the upper limb in people with chronic stroke. Five subjects participated in the training for 30 minutes three times a week for 6 weeks. During training, subjects performed reaching movements over a predefined path. When deviation from this path occurred, shoulder and elbow joints received position feedback using restraining forces. We recorded the amount of position feedback used by each subject. During pre- and posttraining assessments, we collected data from clinical scales, isometric strength, and workspace of the arm. All subjects showed improvement on one or several kinematic variables during a circular motion task after training. One subject showed improvement on all clinical scales. Subjects required position feedback between $7.4 \%$ and $14.7 \%$ of training time. Although augmented feedback use was limited, kinematic outcome measures and movement performance during training increased in all subjects, which was comparable with other studies. Emphasis on movement errors at the moment they occur may possibly stimulate motor learning when movement tasks with sufficiently high levels of difficulty are applied.
\end{abstract}

Key words: arm, augmented feedback, cerebrovascular accident, force feedback, resistive, robot, sensory, stroke, therapy, training.

\section{INTRODUCTION}

Restoring upper-limb function is a major aim in stroke rehabilitation. Of the people who experienced a stroke, 30 to 66 percent do not have proper arm-hand function after six months [1]. Restoration of arm-hand function is crucial to improving independence. Improving lost function is stimulated through motor relearning during stroke rehabilitation. The literature shows that several elements of training contribute to motor relearning [2]. Repetitive, active training of functional tasks in a meaningful environment is known to improve motor control, functional recovery, and strength in upper-limb stroke rehabilitation [2-8]. Using appropriate feedback to enhance motor learning and motivate the patient is an essential part of the training [9-10].

\footnotetext{
Abbreviations: $\mathrm{AR}=$ axial rotation, $\mathrm{ARAT}=$ Action Research Arm Test, CCW = counterclockwise, $\mathrm{CW}=$ clockwise, EA = elevation angle, $\mathrm{EE}=$ elbow excursion, $\mathrm{EF}=$ elbow flexion, $\mathrm{EP}=$ plane of elevation, FMA-UL = Fugl-Meyer Assessment UpperLimb (subscale), MI = Motricity Index, MVT = maximal voluntary torque.

*Address all correspondence to Birgit I. Molier, MSc; Roessingh Research and Development, Roessinghsbleekweg 33B, Enschede 7522AH, the Netherlands; 0031534875741; fax: 0031-534340849. Email: b.molier@rrd.nl DOI:10.1682/JRRD.2010.07.0128
} 
Feedback refers to a person's sensory-perceptual awareness regarding their interaction with the environment. This information can be available as sound, vision, or sensation during or after the movement is performed. Since intrinsic feedback mechanisms are often impaired after stroke, providing augmented feedback is thought to be beneficial. Augmented feedback by sound, vision, or touch may be provided to enhance task performance or goal achievement [11-12]. Using forces applied to the upper limb during movement as augmented feedback might activate the internal proprioceptive system more than during normal movement. Using a robotic device, augmented feedback regarding the position of the arm during movement can be provided by resistance forces when the patient deviates from a predefined path [13].

The goal of this pilot study is to better understand the effect of position feedback use during task-oriented reach training of the upper limb in people with chronic stroke. We expect to find improvements in arm movement ability on both kinematic outcome measures and clinical scales. We also expect more position feedback use when the difficulty level of training increases.

\section{METHODS}

This pilot study comprised a 6-week training period. Prior to training, we performed two measurement sessions (spaced 1 week apart) on subjects to identify a possible baseline trend. After the training period, we performed a posttraining evaluation measurement session.

\section{Subjects}

This study included five people with chronic stroke. Inclusion criteria were left hemispheric stroke and the ability to move the upper limb slightly against gravity. We excluded subjects if they had shoulder pain or were $<6$ months poststroke. Table 1 presents the subjects' ages, affected sides, hand dominance, and time poststroke.

\section{Training}

Training sessions took place three times a week for 30 minutes supervised by a trained physical therapist. The training program consisted of three active reaching tasks: task 1, sliding the hand over the table; task 2, lifting and moving the hand above the table; and task 3, lifting and moving the hand to a shelf. Figure 1 illustrates the different tasks. Subjects performed these reaching
Table 1.

Subject characteristics.

\begin{tabular}{clccc}
\hline Subject & Sex & $\begin{array}{c}\text { Age } \\
(\mathbf{y r})\end{array}$ & $\begin{array}{c}\text { Hand } \\
\text { Dominance }\end{array}$ & $\begin{array}{c}\text { Time Poststroke } \\
\text { (mo) }\end{array}$ \\
\hline 1 & Female & 50.8 & Right & 30 \\
2 & Male & 53.4 & Right & 44 \\
3 & Female & 68.7 & Right & 51 \\
4 & Male & 59.8 & Right & 20 \\
5 & Male & 57.5 & Left & 32 \\
\hline \multicolumn{7}{ll}{ Note: Right affected side in all subjects. } \\
\hline
\end{tabular}

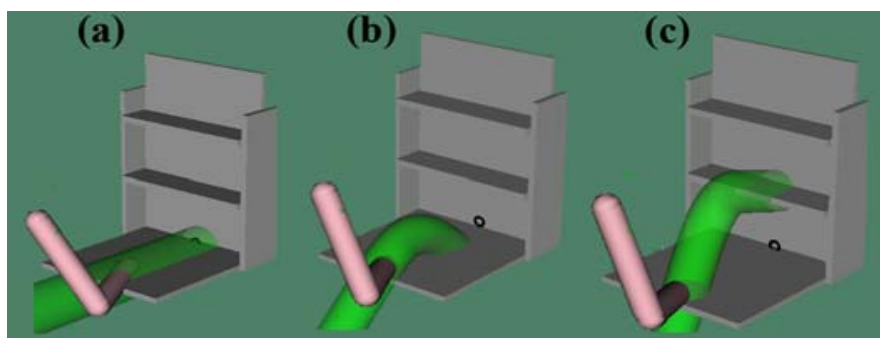

Figure 1.

Virtual representation of movement exercises and corresponding virtual tabletop in three-dimensional views. Starting point of task is close to body and in front of trunk. Hand is then moved farther from body in same column. (a) Moving hand (task 1). (b) Moving hand to another field by making curve (task 2). (c) Lifting hand to shelf (task 3).

exercises on a tabletop divided into nine squares (three in each row) of $15 \times 15 \mathrm{~cm}$. For task 3, subjects used two additional shelves, each with three squares of $15 \times 15 \mathrm{~cm}$, at 25 and $45 \mathrm{~cm}$ above the table.

The physical therapist determined the succession of the tasks, difficulty level (ascending from tasks 1 to 3), and diameter of the predefined path (as represented by a virtual tunnel). Subjects started the reaching task with their hand in front of the midline and as close as possible to their trunk. This position corresponded with placing the hand on the front row in the middle square.

\section{Feedback}

A virtual tunnel, a zone in which the subject is free to move, represented the predefined path. Each time subjects moved outside the virtual tunnel, they received position feedback. Position feedback provided resistance on the shoulder and elbow joints, preventing movements, to make subjects aware that they deviated from the predefined path. To have the feedback forces removed, subjects needed to actively correct their path by moving 
back toward the virtual tunnel. At this point, the reach movement could continue within the virtual tunnel toward the target. During the exercises, subjects could see their own arm and the table with its movement goals. The virtual tunnel was visible on a computer monitor only to the therapist. Subjects experienced the feedback solely as resistance on their arm without any additional visual or auditory cues.

\section{Exoskeleton}

A robotic exoskeleton device (Dampace [Figure 2]) provided the resistive forces. It has been used in previous experiments [14-15].

This device has three degrees of freedom at the shoulder: shoulder plane of elevation (EP, corresponding with clinical terms of shoulder horizontal abduction and/ or adduction), shoulder elevation angle (EA, corresponding with shoulder anteflexion or shoulder abduction), and axial rotation (AR, corresponding with endorotation and/ or exorotation). It also has one degree of freedom at the elbow: elbow flexion (EF) and elbow extension. These joint angles (Figure 3) are defined according to the recommendations of Wu et al. and the International Society of Biomechanics [16]. The device applied resistive forces to each of these four axes individually [14].

We attached the device to the subject's upper arm and forearm using soft straps. A flexible wrist attachment allowed pronation and supination of the forearm without force control. The device was attached to a rigid frame, situated behind the subject, in such a way that the shoul-

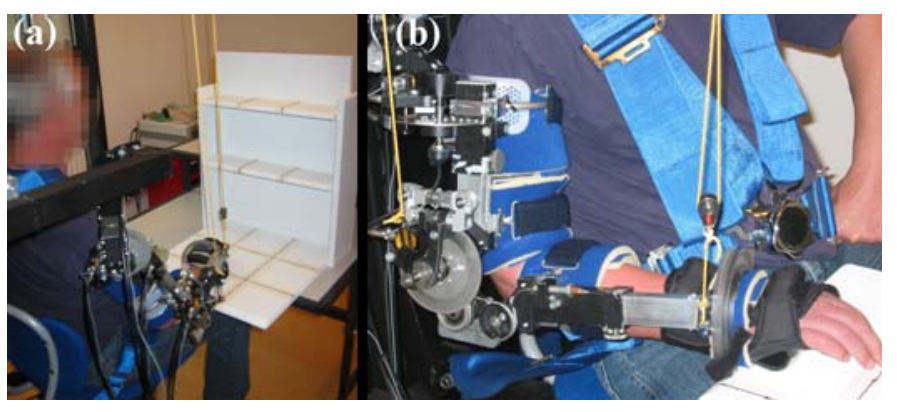

Figure 2.

(a) Subject in exoskeleton ${ }^{*}$ performing reaching movements on tabletop. (b) Close-up of exoskeleton arm, with upper arm and forearm in soft straps. *Stienen AH, Hekman EE, Prange GB, Jannink MJ, Aalsma AM, Van der Helm FC, Van der Kooij H. Dampace: Design of an exoskeleton for force-coordination training in upper-extremity rehabilitation. ASME J Med Dev. 2009;3(3):1-10.

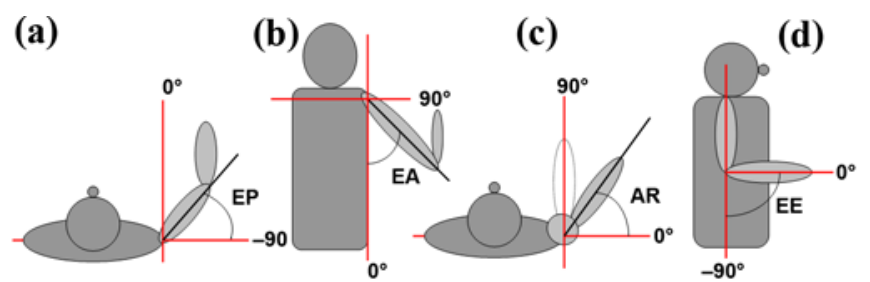

Figure 3.

Graphical representation of joint angles: (a) shoulder plane of elevation (EP), (b) shoulder elevation angle (EA), (c) axial rotation (AR), and (d) elbow excursion (EE).

der could move freely. To minimize the effect of compensating trunk movements, we strapped the subject to the seat with a four-point safety belt.

Integrated potentiometers measured shoulder rotation, and linear optical encoders measured shoulder translations. A rotational optical encoder measured the EE. The digital values were sampled with a rate of $1 \mathrm{kHz}$, low-pass filtered with a first-order Butterworth filter with a cutoff frequency of $40 \mathrm{~Hz}$, and stored on a computer with a sample frequency of $20 \mathrm{~Hz}$. Before analysis, all measured signals were off-line filtered with a first-order, zero phase-shift, low-pass Butterworth filter with a cutoff frequency of $5 \mathrm{~Hz}$.

\section{Data Collection}

During pre- and posttraining evaluations, we measured arm-movement ability changes using the Fugl-Meyer Assessment Upper-Limb (FMA-UL) subscale, the Motricity Index (MI), the Action Research Arm Test (ARAT), circular arm movements, and isometric strength.

\section{Clinical Assessments}

For the FMA-UL (maximum score: 66 points), subjects perform upper-limb movements ranging from gross movements of the shoulder and elbow to detailed finger movements. The upper-limb portion of the MI (maximum score: 100 points) measures maximal isometric muscular strength. During the ARAT (maximum score: 57 points), subjects manipulate various objects. Higher scores on all scales represent better performance. The same investigator performed all tests during each evaluation.

\section{Circular Arm Movements}

Subjects made two sets of five consecutive circular motions above a tabletop: one set clockwise (CW) and 
one set counterclockwise (CCW). Subjects started the circular motion task with their hand in front of the midline and as close as possible to their trunk. They performed movements at a self-selected speed. The tabletop showed templates of circles of different radii to motivate subjects to make the circles as large and round as possible. We randomized the order of direction of the circular motion task (CW or CCW) across subjects and sessions.

The device recorded joint excursions of shoulder and elbow in "free mode" without applying any forces during circular arm movements. To calculate the hand position, we transformed joint angles into joint positions using segment lengths of the upper arm (defined as the distance between the acromion and the lateral epicondyle of the humerus) and forearm (defined as the distance between the lateral epicondyle of the humerus and the third metacarpophalangeal joint). Joint positions were expressed relative to the shoulder position by defining the position of the shoulder joint as the origin to exclude contributions of compensatory trunk movements.

From the hand position data, we deduced the circular movement made by the subject. We extracted individual circles from the data between two minima of the Euclidian distance in the horizontal plane between the hand and the shoulder joint. We connected start and end positions of the circle to ensure a closed curve. We selected the three largest circles for each subject after a visual inspection for completeness and correctness.

To represent workspace, we calculated the active range of motion as the area enclosed by the projection of the hand path onto the tabletop. Corresponding joint excursions (EP, EA, AR, and EE) during each circular movement represented movement coordination. We averaged these parameters over the three selected circles. We pooled data from the CW and CCW circular motions using a paired-samples Student $t$-test $(p>0.05)$ after confirming that no significant differences existed.

\section{Isometric Strength}

Subjects performed three maximal contractions of isometric elbow extensions. The contractions were spaced $1 \mathrm{~min}$ apart to minimize fatigue. We used the maximum value sustained for $0.25 \mathrm{~s}$ of the three performed extensions as the maximal voluntary torque (MVT). The subjects started with their upper limb in $80^{\circ}$ of shoulder abduction and $90^{\circ}$ of elbow flexion. The investigator provided verbal encouragement during elbow extensions.
A custom-built six degrees of freedom force-torque sensor based on strain gauges measured the MVT. These sensors measured forces and torques simultaneously in three directions and were real-time filtered with a fourthorder Butterworth low-pass filter with a cutoff frequency of $10 \mathrm{~Hz}$. We stored the data with a sample rate of $100 \mathrm{~Hz}$ on a computer.

\section{Feedback}

In addition to these evaluations, we collected data during training about the frequency of position feedback (as described in the earlier "Feedback" section) to study the actual contribution of position feedback to the training. We recorded the total number of collisions with the virtual wall within each training session along with the total number of movements in that session. We calculated the average use of position feedback during the entire training period as the percentage of collisions with respect to the total number of movements for each session, averaged over all training sessions. To indicate changes in difficulty level during the training, we recorded additional information about the height and diameter of the virtual tunnel.

\section{Data Analysis}

Initial analysis of the data obtained during baseline measurements revealed some variations in motor performance (in clinical tests, circular motion, and strength tasks), but we saw no clear trend in one direction. Therefore, we averaged the data of the baseline measurements and compared them per subject with the data obtained during the posttraining evaluation measurements. We calculated the differences between pre- and posttraining evaluations. In addition, we used scatter plots for each subject to study the relationship between changes in different outcome measures.

\section{RESULTS}

\section{Clinical Assessment}

Figure 4 presents individual baseline scores of the FMA-UL, ARAT, and MI together with the absolute difference of the scores posttraining. Four subjects improved on the FMA-UL by between 1.0 and 9.5 points. On the MI, two subjects improved by 8 and 13 points each. Four subjects improved on the ARAT by between 0.5 and 5.0 points. 
(a)

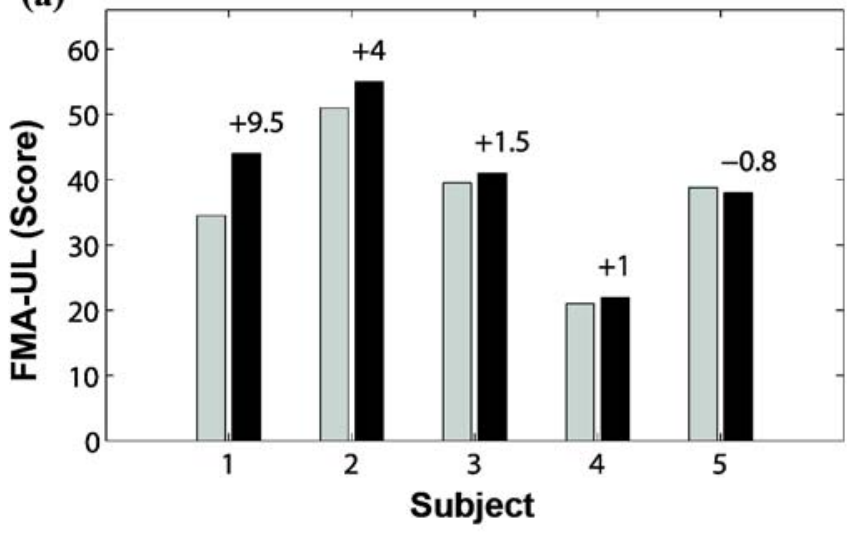

(c)

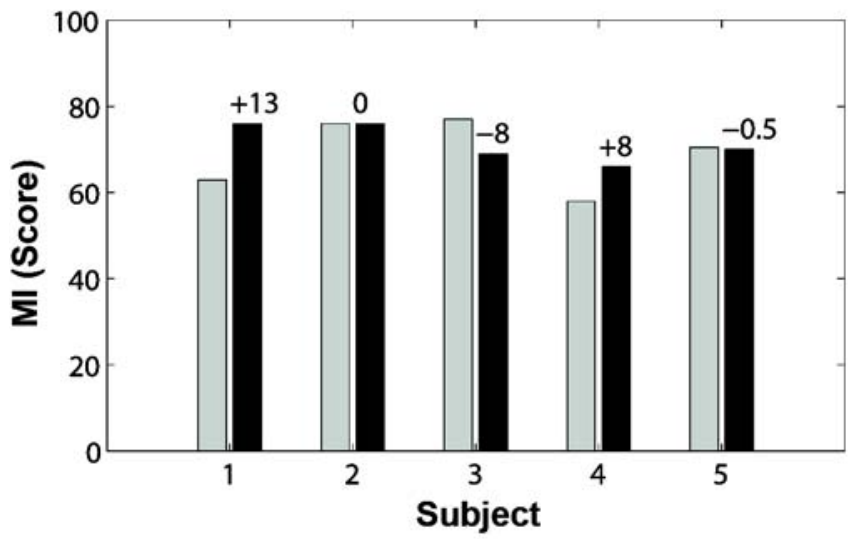

(b)

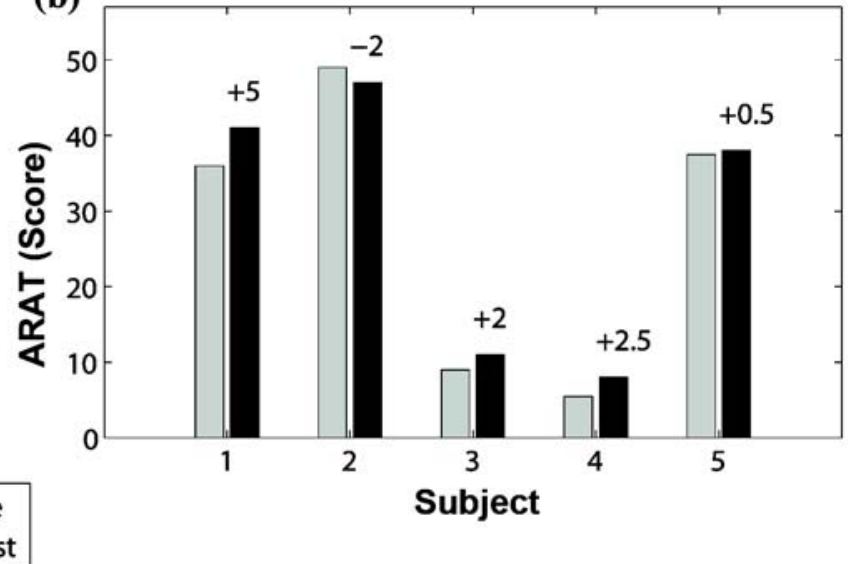

(d)

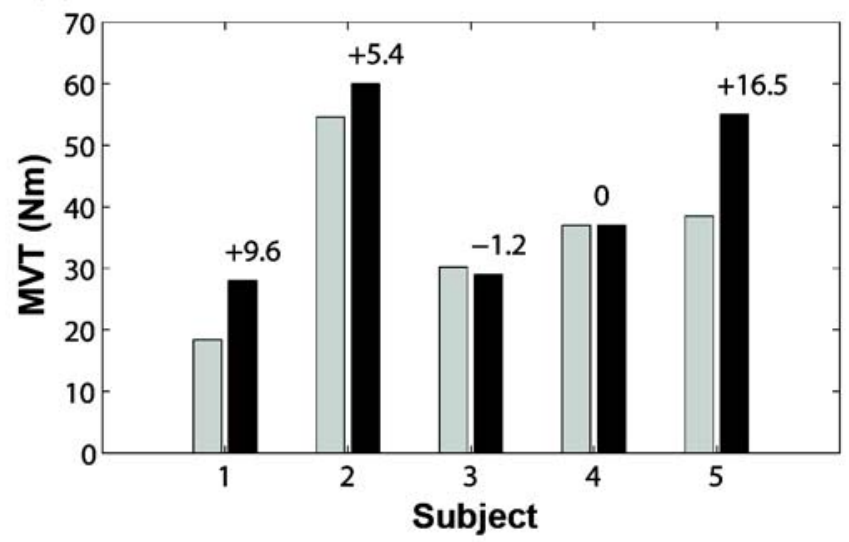

Figure 4.

(a) Fugl-Meyer Assessment upper-limb subscale (FMA-UL), (b) Action Research Arm Test (ARAT), (c) Motricity Index (MI), and (d) maximal voluntary torque (MVT) values with absolute values before (pre) and after (post) training.

\section{Circular Arm Movements}

Three subjects showed improvement on increasing their workspace by between 20.2 and 63.4 percent. Three subjects improved their range of EP by between $5.2^{\circ}$ and $10.6^{\circ}(8.0 \%-12.6 \%)$. Two subjects decreased their range of EP with $3.5^{\circ}$ and $18.2^{\circ}(4.8 \%$ and $23.8 \%)$ each. All subjects showed shoulder EA improvement by between $0.9^{\circ}$ and $6.5^{\circ}$ (9.5\%-97.0\%). The EE range improved for all subjects by between $1.5^{\circ}$ and $17.3^{\circ}(2.7 \%-57.5 \%)$.

\section{Isometric Strength}

Figure 4 displays the MVT of all subjects together with the absolute difference of the score posttraining. Three subjects showed improvement on their MVT by between 5.4 and $16.5 \mathrm{Nm}$ (9.9\%-52.2\%).

\section{Feedback}

In general, subjects performed around 100 movements per training session. Every subject participated in at least 15 sessions. Figure 5 displays the percentage errors, tunnel diameter, and movement height per session for all five subjects for the entire training period.

The difficulty of the exercises increased during training, characterized by the increased height of the movement and decreased tunnel diameter (Figure 5). This indicates improved movement performance during the training period for all subjects.

Average use of position feedback during the training period was between 7.4 percent and 14.7 percent (Table 2). During training, position feedback use changed independent of changes in difficulty of the exercises. 

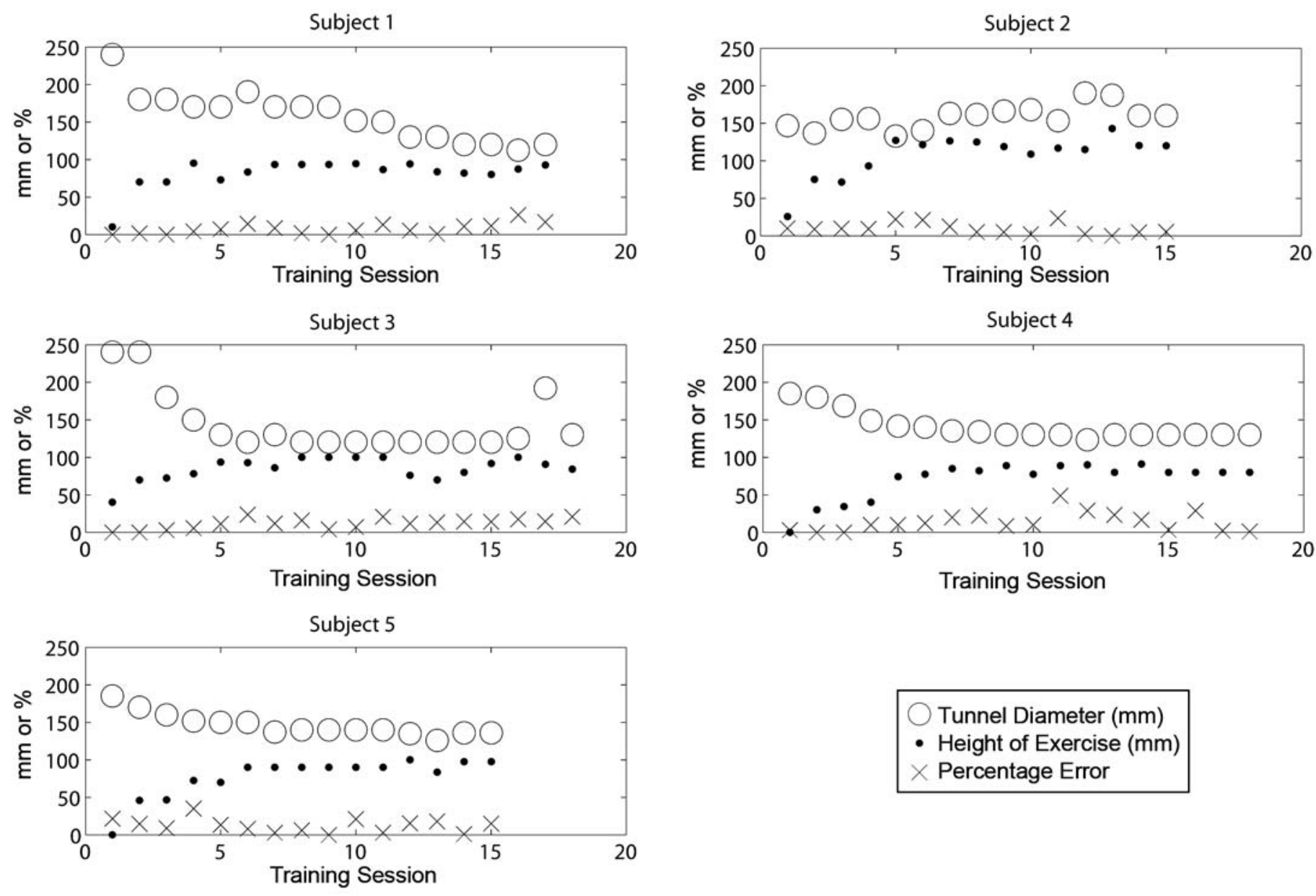

Figure 5.

Percentage error, tunnel diameter, and height of movement per session for entire training period for all five subjects.

Table 2.

Average use of position feedback (\% errors) per subject over all sessions.

\begin{tabular}{cc}
\hline Subject & Average \% Error \\
\hline 1 & 7.4 \\
2 & 9.3 \\
3 & 12.8 \\
4 & 14.7 \\
5 & 12.2 \\
\hline
\end{tabular}

\section{Overall Effect}

Subject 1 showed improvement on all outcomes measures. Subjects 2 and 5 showed improvement on both MVT and kinematic outcome measures. Subjects 3 and 4 showed varying results over all outcome measures.

Improvement in workspace seems to coincide with improved MVT and improved shoulder EA excursions and elbow joint excursions. This is illustrated in scatter plots of the relative improvement percentage with respect to the baseline score per subject of circle area versus MVT, circle area versus shoulder EA, and circle area versus elbow excursion (Figure 6).

\section{DISCUSSION}

Our objective was to better understand the effect of position feedback during task-oriented reach training of the upper limb in people with chronic stroke. We observed improvement in kinematic outcome measures for all subjects, but only one subject showed improvement on clinical scales. Other studies using forces for 
(a)

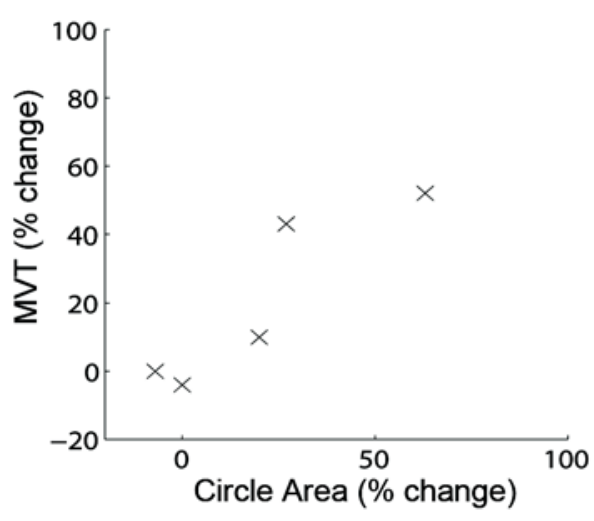

(b)

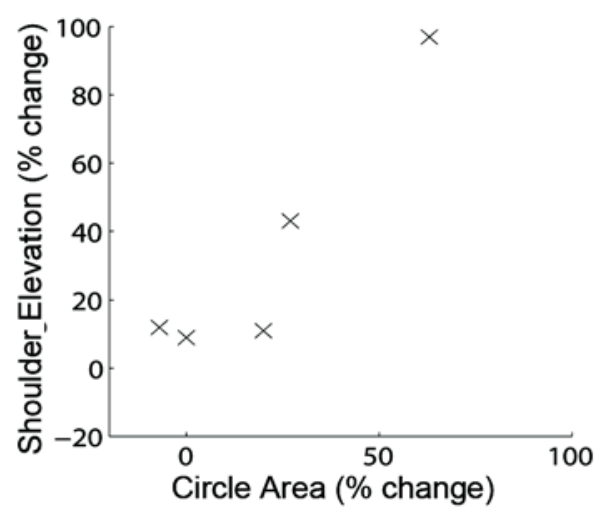

(c)

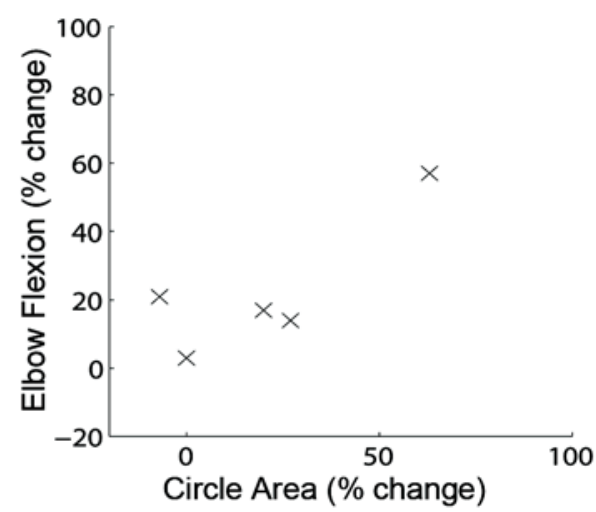

Figure 6.

Relative improvement in percentage of baseline score per subject. (a) Circle area versus maximal voluntary torque (MVT). (b) Circle area versus shoulder elevation angle. (c) Circle area versus elbow flexion.

emphasizing errors during reach training found similar improvement on kinematic outcome measures [17-19].

In our study, feedback made subjects aware of their errors at the moment the error was made. Subjects needed to actively correct their movement before the feedback forces were removed and the movement could be continued. Several studies have suggested that this type of augmented feedback, provided by placing emphasis on errors during rehabilitation therapy, is potentially beneficial for motor learning [20-21]. Also, the direct response of the movement error by means of augmented feedback is thought to contain components that stimulate motor learning. Shabbott and Sainburg tested the timing effect of augmented feedback in nondisabled subjects during a visuomotor task [22]. The group receiving feedback after the completed movement showed less improvement on the learned task than the group receiving feedback during movement execution. In the same study, Shabbott and Sainburg tested whether this observed difference in learning could be caused by the (in)ability to correct for movements during reaching. They observed no difference in reaching performance between the group that corrected their errors during the movement and the group that did not [22]. This might indicate that availability of knowledge of movement errors at the moment they occur seems to be more important for motor learning than the ability to correct movement errors.

In the present study, we provided augmented feedback in addition to the available intrinsic feedback. This resulted in the actual use of augmented feedback in 7.4 to
14.7 percent of movements. Despite this limited use of augmented feedback, subjects showed improved movement ability during and after training, which was also reflected in the increasing difficulty level during training. Other studies that showed similar improvement used augmented feedback 20 percent or more of the time during training, but provided no data on how many subjects actually used it [23-25]. A possible explanation for improvement in training results, together with limited augmented feedback use, could be that this augmented feedback does not substantially activate the internal proprioceptive system. The tasks used in this study may not have been that demanding, so they could have largely been executed solely using the present intrinsic feedback mechanisms. More complex movement tasks could contribute to a higher use of augmented feedback. This could be achieved by applying a visual distortion task, creating a mismatch between the intrinsic and augmented feedback systems. This would enable specific testing of the effect of augmented feedback on motor learning in both nondisabled subjects and people with stroke.

In all, we observed improvement on kinematic outcome measures and movement performance during training for all subjects and improvement on clinical scales for one subject, even though augmented feedback use was limited. Since these changes are in line with comparable studies, it seems that the available augmented feedback may have contributed to this, although direct comparison with a control group is needed for confirmation. Findings from the present study and available literature further 
suggest that emphasis on movement errors at the moment they occur can potentially stimulate motor learning, but applying sufficiently high difficulty levels during movement tasks is important.

\section{CONCLUSIONS}

Although the augmented feedback was used in a limited amount of movements, kinematic outcome measures and movement performance during training increased in all subjects. These changes are comparable with other studies applying error feedback. We suggest that emphasis on errors at the moment they occur may possibly stimulate motor learning when patients perform movement tasks with sufficiently high difficulty levels.

\section{ACKNOWLEDGMENTS}

\author{
Author Contributions: \\ Study design: B. I. Molier, M. J. A. Jannink, H. J. Hermens, \\ A. H. A. Stienen, G. B. Prange, H. van der Kooij. \\ Robotic device design and construction: A. H. A. Stienen. \\ Subject recruitment: B. I. Molier. \\ Acquisition of data: B. I. Molier. \\ Analysis of data: T. Krabben. \\ Interpretation of results: B. I. Molier, G. B. Prange. \\ Drafting of manuscript: B. I. Molier. \\ Critical revision of manuscript for important intellectual content: \\ T. Krabben, G. B. Prange, J. H. Buurke, H. J. Hermens.
}

Financial Disclosures: The authors have declared that no competing interests exist.

Funding/Support: This material was based on work supported by the Ministry of Economic Affairs (EZ), Overijssel, and Gelderland, the Netherlands (grant 1-15160).

Institutional Review: All subjects provided informed consent. The local ethics board approved the experimental protocol.

Participant Follow-Up: The authors do not plan to inform participants of the publication of this study.

\section{REFERENCES}

1. Kwakkel G, Kollen BJ, Van der Grond J, Prevo AJ. Probability of regaining dexterity in the flaccid upper limb: Impact of severity of paresis and time since onset in acute stroke. Stroke. 2003;34(9):2181-86. [PMID: 12907818] DOI:10.1161/01.STR.0000087172.16305.CD

2. Timmermans AA, Seelen HA, Willmann RD, Kingma $H$. Technology-assisted training of arm-hand skills in stroke: Concepts on reacquisition of motor control and therapist guidelines for rehabilitation technology design. J Neuroeng Rehabil. 2009;6:1. [PMID: 19154570]

DOI:10.1186/1743-0003-6-1

3. Kwakkel G. Impact of intensity of practice after stroke: Issues for consideration. Disabil Rehabil. 2006;28(13-14): 823-30. [PMID: 16777769] DOI:10.1080/09638280500534861

4. Schaechter JD. Motor rehabilitation and brain plasticity after hemiparetic stroke. Prog Neurobiol. 2004;73(1):61-72. [PMID: 15193779]

DOI:10.1016/j.pneurobio.2004.04.001

5. Hodics T, Cohen LG, Cramer SC. Functional imaging of intervention effects in stroke motor rehabilitation. Arch Phys Med Rehabil. 2006;87(12 Suppl 2):S36-42. [PMID: 17140878] DOI:10.1016/j.apmr.2006.09.005

6. Lotze M, Braun C, Birbaumer N, Anders S, Cohen LG. Motor learning elicited by voluntary drive. Brain. 2003; 126(Pt 4):866-72. [PMID: 12615644$]$

DOI:10.1093/brain/awg079

7. Kaelin-Lang A, Sawaki L, Cohen LG. Role of voluntary drive in encoding an elementary motor memory. J Neurophysiol. 2005;93(2):1099-1103. [PMID: 15456807] DOI:10.1152/jn.00143.2004

8. Barreca S, Wolf SL, Fasoli S, Bohannon R. Treatment interventions for the paretic upper limb of stroke survivors: A critical review. Neurorehabil Neural Repair. 2003;17(4): 220-26. [PMID: 14677218] DOI:10.1177/0888439003259415

9. Henderson A, Korner-Bitensky N, Levin M. Virtual reality in stroke rehabilitation: A systematic review of its effectiveness for upper limb motor recovery. Top Stroke Rehabil. 2007;14:52-61. [PMID: 17517575] DOI:10.1310/tsr1402-52

10. Holden MK. Virtual environments for motor rehabilitation: Review. Cyberpsychol Behav. 2005;8(3):187-219.

[PMID: 15971970] DOI:10.1089/cpb.2005.8.187

11. Van Vliet PM, Wulf G. Extrinsic feedback for motor learning after stroke: What is the evidence? Disabil Rehabil. 2006;28(13-14):831-40. [PMID: 16777770] DOI:10.1080/09638280500534937

12. Molier BI, Van Asseldonk EH, Hermens HJ, Jannink MJ. Nature, timing, frequency, and type of augmented feedback; does it influence motor relearning of the hemiparetic arm after stroke? A systematic review. Disabil Rehabil. 2010;32(22):1799-1809. [PMID: 20345249]

DOI:10.3109/09638281003734359

13. Prange GB, Jannink MJ, Groothuis CG, Hermens HJ, IJzerman MJ. A systematic review of the effect of robotaided therapy on recovery of the hemiparetic arm after stroke. J Rehabil Res Dev. 2006;43(2):171-84. 
[PMID: 16847784$]$

DOI:10.1682/JRRD.2005.04.0076

14. Stienen AH, Hekman EE, Prange GB, Jannink MJ, Aalsma AM, Van der Helm FC, Van der Kooij H. Dampace: Design of an exoskeleton for force-coordination training in upperextremity rehabilitation. ASME J Med Dev. 2009;3(3):1-10.

15. Prange GB, Kallenberg LA, Jannink MJ, Stienen AH, Van der Kooij H, IJzerman MJ, Hermens HJ. Influence of gravity compensation on muscle activity during reach and retrieval in healthy elderly. J Electromyogr Kinesiol. 2009; 19(2):e40-49. [PMID: 17911029]

DOI:10.1016/j.jelekin.2007.08.001

16. Wu G, Van der Helm FC, Veeger HE, Makhsous M, Van Roy P, Anglin C, Nagels J, Karduna AR, McQuade K, Wang X, Werner FW, Buchholz B; International Society of Biomechanics. ISB recommendation on definitions of joint coordinate systems of various joints for the reporting of human joint motion-Part II: Shoulder, elbow, wrist and hand. J Biomech. 2005;38(5):981-92. [PMID: 15844264] DOI:10.1016/j.jbiomech.2004.05.042

17. Rozario SV, Housman S, Kovic M, Kenyon RV, Patton JL. Therapist-mediated post-stroke rehabilitation using haptic/ graphic error augmentation. Conf Proc IEEE Eng Med Biol Soc. 2009;2009:1151-56. [PMID: 19964499]

18. Volpe BT, Lynch D, Rykman-Berland A, Ferraro M, Galgano M, Hogan N, Krebs HI. Intensive sensorimotor arm training mediated by therapist or robot improves hemiparesis in patients with chronic stroke. Neurorehabil Neural Repair. 2008;22(3):305-10. [PMID: 18184932]

DOI:10.1177/1545968307311102

19. Kahn LE, Zygman ML, Rymer WZ, Reinkensmeyer DJ. Robot-assisted reaching exercise promotes arm movement recovery in chronic hemiparetic stroke: A randomized controlled pilot study. J Neuroeng Rehabil. 2006;3:12.

[PMID: 16790067$]$

DOI:10.1186/1743-0003-3-12

20. Patton JL, Stoykov ME, Kovic M, Mussa-Ivaldi FA. Evaluation of robotic training forces that either enhance or reduce error in chronic hemiparetic stroke survivors. Exp Brain Res. 2006;168(3):368-83. [PMID: 16249912]

DOI:10.1007/s00221-005-0097-8
21. Van Asseldonk EH, Wessels M, Stienen AH, Van der Helm FC, Van der Kooij H. Influence of haptic guidance in learning a novel visuomotor task. J Physiol Paris. 2009;103(35):276-85. [PMID: 19665551] DOI:10.1016/j.jphysparis.2009.08.010

22. Shabbott BA, Sainburg RL. Learning a visuomotor rotation: Simultaneous visual and proprioceptive information is crucial for visuomotor remapping. Exp Brain Res. 2010; 203(1):75-87. [PMID: 20237773] DOI:10.1007/s00221-010-2209-3

23. Merians AS, Jack D, Boian R, Tremaine M, Burdea GC, Adamovich SV, Recce M, Poizner H. Virtual realityaugmented rehabilitation for patients following stroke. Phys Ther. 2002;82(9):898-915. [PMID: 12201804]

24. Cirstea CM, Ptito A, Levin MF. Feedback and cognition in arm motor skill reacquisition after stroke. Stroke. 2006; 37(5):1237-42. [PMID: 16601218] DOI:10.1161/01.STR.0000217417.89347.63

25. Cirstea MC, Levin MF. Improvement of arm movement patterns and endpoint control depends on type of feedback during practice in stroke survivors. Neurorehabil Neural Repair. 2007;21(5):398-411. [PMID: 17369514] DOI:10.1177/1545968306298414

Submitted for publication August 10, 2010. Accepted in revised form March 25, 2011.

This article and any supplementary material should be cited as follows:

Molier BI, Prange GB, Krabben T, Stienen AH, Van der Kooij H, Buurke JH, Jannink MJ, Hermens HJ. Effect of position feedback during task-oriented upper-limb training after stroke: Five-case pilot study. J Rehabil Res Dev. 2011;48(9):1109-18.

DOI:10.1682/JRRD.2010.07.0128

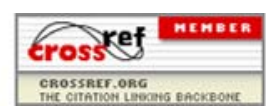


